\title{
A STUDY ON THE CONCEPTS OF DESIGN THINKING
}

\author{
Mrs. P. Deepa \\ Assistant Professor, MBA \\ SRMIST Ramapuram, Chennai, Tamil Nadu, India
}

\begin{abstract}
This study was proposed to acquire knowledge on the concept of Design thinking and how it works, how can it be implemented into business, real life etc. Design Thinking revolves around a deep interest in developing an understanding of the people for whom we're designing the products or services. It helps us observe and develop empathy with the target user. Design Thinking helps us in the process of questioning: questioning the problem, questioning the assumptions, and questioning the implications. Design Thinking is extremely useful in tackling problems that are ill-defined or unknown, by re-framing the problem in human-centric ways, creating many ideas in brainstorming sessions, and adopting a hands-on approach in prototyping and testing. Design Thinking also involves on-going experimentation: sketching, prototyping, testing, and trying out concepts and ideas.
\end{abstract}

Key words: Design Thinking, human-centric, hands-on approach, prototyping and testing

\section{INTRODUCTION}

Design thinking is an iterative process in which we seek to understand the user, challenge, assumptions and redefine problems in an attempt to identify alternative strategies and solutions that might not be instantly apparent with our initial level of understanding. At the same time, Design thinking provides a solution-based approach to solving problems. It is a way of thinking and working as well as a collection of hands-onmethods.

Design thinking is not an exclusive property of designers-all great innovators in literature, art, music, science; engineering and business have practiced it. Design thinking is that designers' work processes can help us systematically extract, teach, learn and apply these human-centred techniques to solve problems in a creative and innovative way- in our designs, in our business, in our countries, in our lives.

Some of the world's leading brands, such as Apple, Google, Samsung and GE, have rapidly adopted the Design Thinking approach, and Design Thinking is being taught at leading universities around the world, including school, Stanford, Havard and MIT.

Design Thinking revolves around a deep interest in developing an understanding of the people for whom we're designing the products or services. It helps us observe and develop empathy with the target user. Design Thinking helps us in process of questioning; the problem, assumptions, implications. Design Thinking is extremely useful in tackling problems that are ill-defined or unknown, by re-framing the problem in humancentric ways, creating many ideas in brainstorming sessions, and adopting a hands-on approach in prototyping and testing. Design thinking also involves on going experimentation: sketching, prototyping, testing and trying out concepts and ideas.

Importance of Design thinking in Today's world

Over recent decades, it has become crucial to develop and redefine skills which allow us to understand and act on rapid changes in our environment and behaviour. The world has become increasingly interconnected and complex, and design thinking offers a means to grapple with all this change in a more human-centric manner.

Design teams use design thinking to tackle ill-defined or unknown problems (otherwise known as wicked problems) because the process reframes these problems in human-centric ways and allows designers to focus on what's most important for users. Design thinking offers us a means to think outside the box and also dig that bit deeper into problem solving. It helps designers carry out the right kind of research, create prototypes and test out products and services to uncover new ways to meet users' needs.

The design thinking process has become increasingly popular over the last few decades because it was a key to the success of many highprofile, global organizations-companies such as Google, Apple and Airbnb have wielded it to notable effect, for example. This outside the box thinking is now taught at leading universities across the world and is encouraged at every level of business.

Design thinking improves the world around us every day because of its ability to generate ground-breaking solutions in a disruptive and innovative way. Design thinking is more than 


\section{International Journal of Engineering Applied Sciences and Technology, 2020 Vol. 4, Issue 12, ISSN No. 2455-2143, Pages 269-272 \\ Published Online April 2020 in IJEAST (http://www.ijeast.com)}

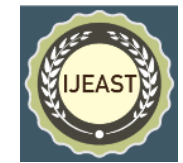

just a process, it opens up an entirely new way to think, and offers a collection of hands-on methods to help you apply this new mind set.

\section{LITERATURE REVIEW}

Instead, the suggested solutions are better or worse as opposed to right or wrong and it can take a long time to evaluate solutions, which ramify throughout the system (Buchanan, 1992). Design thinking (DT) is a design philosophy that offers a possible approach to design problems of this complicated nature (Liedtka, 2015) and is suitable for radical (and incremental) innovation (Fleury et al., 2016). The ability of DT to facilitate the development of possible solutions to wicked problems, by fostering learning and managing uncertainty (Beckman and Barry, 2007), thus seems highly relevant in a CBMI context.

The ability of DT to incorporate opposing perspectives applies both at the top level, for conflicts between customer needs, market opportunities, technological and economic constraints, and at the team level, for conflicting viewpoints between innovation team members. In fact, this kind of conflict is perceived as a driving force for creativity in DT termed 'creative friction' (Fleury et al., 2016) and multidisciplinary teams incorporating formally trained designers as well as non-designers is indeed encouraged to exploit such friction (Carlgren et al., 2016a). This ability of DT to integrate multiple viewpoints is relevant in a CBMI context, where multiple actors are oftentimes indispensable to create systems innovation (Antikainen and Valkokari, 2016; Geissdoerfer et al., 2018a), and DT has been found useful in the related context of sustainable BMI (Geissdoerfer et al., 2016).

Definitions, terminology and the number of process steps described for DT vary somewhat in the literature (d.school, n.d.; Brown, 2008;Seidel and Fixson, 2013;Carlgren et al., 2016b;Fleury et al., 2016). Liedtka (2015) nevertheless concludes that there are some typical characteristics of this type of innovation process: "All descriptions of the process emphasise iterative cycles of exploration using deep user research to develop insights and design criteria, followed by the generation of multiple ideas and concepts and then prototyping and experimentation to select the best ones -usually performed by functionally diverse groups working closely with users."

\section{An Example of Problem solving: The Encumbered Vs. the fresh Mind}

Thinking outside of the box can provide an innovative solution to a sticky problem. However, thinking outside of the box can be a real challenge as we naturally develop patterns of thinking that are modelled on the repetitive activities and commonly accessed knowledge we surround ourselves with.

Some years ago, an incident occurred where a truck driver tried to pass under a low bridge. But he failed, and the truck was lodged firmly under the bridge. The driver was unable to continue driving through or reverse out.

The story goes that as the truck became stuck, it caused massive traffic problems, which resulted in emergency personnel, engineers, fire fighters and truck drivers gathering to devise and negotiate various solutions for dislodging the trapped vehicle.

Emergency workers were debating whether to dismantle parts of the truck or chip away at parts of the bridge. Each spoke of a solution which fitted within his or her respective level of expertise.

A boy walking by and witnessing the intense debate looked at the truck, at the bridge, then looked at the road and said nonchalantly," Why not just let the air out of the tires?" to the absolute amazement of all the specialists and experts trying to unpick the problem.

When the solution was tested, the truck was able to drive free with ease, having suffered only the damage caused by its initial attempt $t$ ass underneath the bridge. The story symbolizes the struggles we face where oftentimes the most obvious solutions are the ones hardest to come by because of the self-imposed constraints we work within.

\section{Science and Rationality in Design thinking}

Some of the scientific activities will include analysing how users interact with products and investigating the conditions in which they operate: researching user needs, pooling experience from previous projects, considering present and future conditions specific to the product, testing the parameters of the problem, and testing the practical application of alternative problem solutions. Unlike a solely scientific approach, where the majority of known qualities, characteristics, etc. of the problem are tested so as to arrive at a problem solution, Design Thinking investigations include ambiguous elements of the problem to reveal previously unknown parameters and uncover alternative strategies.

After arriving at a number of potential problem solutions, the selection process is underpinned by rationality. Designers are encouraged to analyse and falsify these problem solutions so that they can arrive at the best available option for each problem or obstacle identified during each phase of the design process.

With this in mind, it may be more correct to say that Design Thinking is not about thinking outside of the box, but on its edge, its corner, its flap and under its bar code, as Clint Runge put it. 


\section{THE ORIGIN OF THE 5 STAGE MODEL}

In his 1969 seminal text on design methods, "The Sciences of the Artificial", Nobel prize laureate Herbert Simon outlined one of the first formal models of the Design Thinking process. Simon's model consists of seven major stages, each with component stages and activities, and was largely influential in shaping some of the most widely used Design Thinking process models today. There are many variants of the Design Thinking process in use in the $21^{\text {st }}$ century, and while they may have different numbers of stages ranging from three to seven, they are all based upon the same principles featured in Simon's 1969 model. We focus on the five-stage Design Thinking model proposed by the Hasso-Plattner Institute of Design at Stanford (d.school).

\section{Description}

Stage1: Empathize- Research the User's needs

The first stage of the design thinking process allows gaining an empathetic understanding of the problem, trying to solve, typically through user research. Empathy is crucial to a human-centred design process like design thinking because it allows you to set aside your own assumptions about the world and gain real insight into users and their needs.

Stage 2: Define-State the User's Needs and Problems

This stage accumulates the information created and gathered during the Empathize stage. Observations are analysed synthesised to define the core problems identified so far. The problem statement has to be defined in a human-centred manner.

Stage 3: Ideate-Challenge Assumptions and create ideas.

Designers are ready to generate ideas as they reach the third stage of design thinking. The solid background of knowledge from the first two phases means it can be started to "think outside the box", look for alternative ways to view the problem and identify innovative solutions to the problem statement created.

\section{DESIGN THINKING: A NON-LINEAR PROCESS}

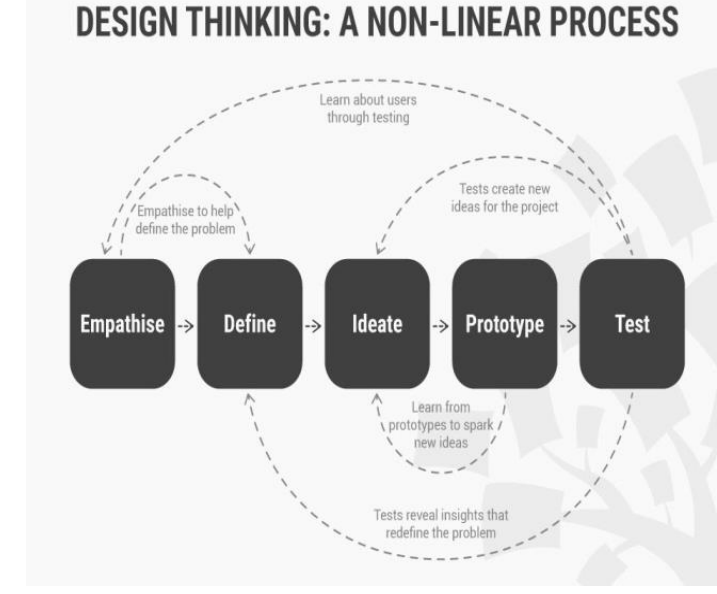

Fig. Stages in Design Thinking

Stage 4: Prototype - Start to create solutions

This is an experimental phase, and the aim is to identify the best possible solution for each of the problems identified during the first three stages. Design teams will produce a number of inexpensive, scaled-down versions of the products ( or specific features found within the product) to investigate the problem solutions generated in the previous stage.

\section{Stage: Test-Try the solutions out}

Designers or evaluators rigorously test the complete product using the best solutions identified in the prototype phase. This is the final phase of the model but, in an iterative process such as design thinking, the results generated are often used to redefine one or more further problems. Designers can then choose to return to previous stages in the process to make further iterations, alterations and refinements to rule out alternative solutions.

\section{DISCUSSION}

In essence, the Design Thinking process is iterative, flexible and focused on collaboration between designers and users, with an emphasis on bringing ideas to life based on how real users think, feel and behave.

Design Thinking tackles complex problems by:

1. Empathising: Understanding the human needs involved.

2. Defining: Re-framing and defining the problem in human-centric ways.

3. Ideating: Creating many ideas in ideation sessions.

4. Prototyping: Adopting a hands-on approach in prototyping.

5. Testing: Developing a prototype/solution to the problem.

\section{CONCLUSION}

Design Thinking is an iterative and nonlinear process. This simply means that the design 
team continuously use their results to review, question and improve their initial assumptions, understandings and results. Results from the final stage of the initial work process inform our understanding of the problem, help us determine the parameters of the problem, enable us to redefine the problem, and, perhaps most importantly, provide us with new insights so we can see any alternative solutions that might not have been available with our previous level of understanding.

\section{REFERENCE}

[1] Don Norman. "Rethinking Design Thinking", 2013:

[2] Gerd Waloszek, Introduction to Design Thinking,2012

[3]Bill Moggridge, "Design Thinking: Dear Don", 2010:

[4]Herbert Simon, The Sciences of the Artificial (3 ${ }^{\text {rd }}$ Edition), 1996

[5] Tim Brown, Change by Design: How Design Thinking Transforms Organizations and Inspires Innovation Introduction, 2009

[6] Kolko, J. (2010) "Abductive Thinking and Sensemaking: Drivers of Design Synthesis", Design Issues, vol. 26, 15-28.

[7] Dorst, Kees; Cross, Nigel (2001). "Creativity in the design process: co-evolution of problemsolution" (PDF). Design Studies. 22 (5): $\quad 425-$ 437. doi:10.1016/S0142-694X(01)00009-6.

[8] Wiltschnig, Stefan; Christensen, Bo; Ball, Linden (2013). "Collaborative problem-solution co-evolution in creative design". Design Studies. 34 (5): $\quad 515-$ 542. doi:10.1016/j.destud.2013.01.002

[9]Plattner, Hasso; Meinel, Christoph; Leifer, Larry J., eds. (2011). Design thinking: understand, improve, apply. Understanding innovation. Berlin; Heidelberg: Springer-Verlag. pp. xivxvi. doi:10.1007/978-3-642-13757-0. ISBN 978-3642-13756-3. OCLC 89832263

[10] Norman, Donald A. (1 January 1986). User Centered System Design. Taylor \& Francis. doi:10.1201/b15703. ISBN 978148222963 9.

[11] Lawson, Bryan. How Designers Think: The Design Process Demystified. London: Architectural, 1980

[12] Rowe, G. Peter (1987). Design Thinking. Cambridge: The MIT Press. ISBN 978-0-26268067-7.

[13] Cross, N. (2018) A Brief History of the Design Thinking Research Symposium Series, Design Studies vol 57, 160-164

[14] Liedtka, Jeanne (September 2018). "Why design thinking works". Harvard Business Review. 96 (5): 72-79.

[15] Brown, Tim. "Design Thinking"." Harvard Business Review, June 2008, pp. 85-92.

Web links: https://www.interaction-design.org/courses/designthinking-the-beginner-s-guide

: https://monoskop.org/images/9/9c/Simon_Herbert _A_The_Sciences_of_the_Artificial_3rd_ed.pdf : https://experience.sap.com/skillup/introductionto-design-thinking/ http://www.core77.com/posts/24579/rethinkingdesign-thinking-24579 http://www.core77.com/posts/17042/designthinking-dear-don-17042 